\title{
Diprenorphine, an antagonist of opioid analgesia, elicits a positive affective state in rats
}

\author{
CAROL M. BEAMAN, GEORGE A. HUNTER, and LARRY D. REID \\ Rensselaer Polytechnic Institute, Troy, New York
}

\begin{abstract}
A dose of diprenorphine, which produces no analgesia, antagonizes the analgesia of other opioids, and facilitates pressing for brain stimulation in rats, was shown to establish a conditioned place preference. This finding provides further support for the conclusion that opioid analgesia and the positive reinforcing characteristics of opioids are separable.
\end{abstract}

Diprenorphine (DIP), an opioid having mixed agonistantagonist activity in certain bioassays, facilitates pressing for electrical intracranial stimulation (ICS) of the lateral hypothalamus (Pollerberg, Costa, Shearman, Herz, \& Reid, 1983). This finding was thought to have significance because DIP is not an analgesic (as measured by the tail-flick test) and completely antagonizes the tail-flick analgesia of fentanyl. These findings (Pollerberg et al., 1983), along with others (Bermudez-Rattoni, CruzMorales, \& Reid, 1983; Bush, Bush, Miller, \& Reid, 1976; Esposito \& Kornetsky, 1978; Farber \& Reid, 1976), provided evidence that opioid analgesia and positive affect (positive reinforcement when made contingent upon an act) are separable.

Rossi and Reid (1976) used the procedures that have come to be known as the conditioned place preference (CPP) test to provide independent evidence that morphine's facilitation of pressing for ICS was related to its ability to elicit positive affect. It was reasoned that if a drug elicited positive affect in one place, the subject subsequently would spend more time there than in a location associated with the effects of a placebo. Recently, the CPP test itself has been studied and found to be an effective procedure for assaying the positive affect elicited by drugs (Mucha, van der Kooy, O'Shaughnessy, \& Bucenieks, 1980).

Although the ability of a drug to enhance pressing rates for ICS is a reasonable index of a drug's positive affective capability (Bozarth, Gerber, \& Wise, 1980), it is not unequivocal (Hunter \& Reid, 1983; Leibman, 1983). What was needed was an independent index of DIP's ability to elicit positive affect. Consequently, we tested DIP using rationale and procedures similar to those of Rossi and Reid (1976).

This research was supported by New York State Health Research Council Grant HRC 13-109. We would like to thank Gaylene Reichert-Hunter, Brian Stanton, Alice Lindsay, and Jean Bestle for their aid in completing this project. Our mailing address is: Department of Psychology, Rensselaer Polytechnic Institute, Troy, NY 12181.

\section{METHOD}

\section{Subjects}

Twenty-four male experimentally naive Sprague-Dawleyderived rats were obtained (Taconic Farms, Germantown, NY) when they weighed about $160 \mathrm{~g}$. After 2 days, and as the procedures began, they were housed individually. Food and water were always available. The colony room was maintained at $24^{\circ} \mathrm{C}$, on a schedule of $12 \mathrm{~h}$ of light per day (lights on at $1000 \mathrm{~h}$ ).

\section{Apparatus}

Four nearly identical $94 \times 19 \times 28.5 \mathrm{~cm}$ wooden boxes were used. Each was divided by guillotine doors into three compartments. The middle compartment $(9 \times 19 \times 28.5 \mathrm{~cm})$ was gray and had a solid wooden floor. One side compartment $(42.5 \mathrm{x}$ $19 \times 28.5 \mathrm{~cm}$ ) had black and white vertical stripes on its walls and a hardware-cloth floor with $1.0 \times 1.0 \mathrm{~cm}$ grids. The other side compartment, of equal size, had black and white horizontal stripes on its walls and floor grids of $1.0 \times 3.6 \mathrm{~cm}$.

\section{Drugs}

Drugs used were morphine sulfate (MOR, $5 \mathrm{mg} / \mathrm{ml}$, Mallinckrodt) and DIP (.025 mg/ml, Reckitt \& Colman). A stock solution of DIP $(5 \mathrm{mg} / \mathrm{ml})$ was prepared in $1 \%$ acetic acid and was further diluted with normal saline. Saline (SAL), the vehicle of the drugs, was used for placebo injections. All injections were given subcutaneously at a volume of $1 \mathrm{ml} / \mathrm{kg}$.

\section{Procedure}

The procedure spanned three blocks of 5 days each, separated by 2 days of no experimental procedures. The first block was to habituate the rats to the boxes and to measure their side preferences. The rats were allowed access to the entire box for $30 \mathrm{~min} /$ day across 4 consecutive days. On the 5 th day, the rats were left in the box for $20 \mathrm{~min}$, and the time spent on each side was tabulated (a baseline measure). A rat was considered to be on a side if at least three paws or the two front paws were on that side.

The conditioning procedure involved injecting rats $30 \mathrm{~min}$ before they were placed in one side of the box for $30 \mathrm{~min}$. The rats were divided into three groups (to receive test agents MOR, DIP, or SAL), with eight rats per group. Four rats from each group received their putative conditioning on their preferred side, and four on their nonpreferred side (determined from baseline data). Each set of four was again divided in half to determine whether a rat received drug or placebo on the first conditioning day. Thereafter, drug and placebo injections were alternated daily. The rats were placed on the side of putative conditioning when under the influence of the test drug. On alternate days, the rats were placed on the opposite side. After 
4 conditioning days, 2 with placebo and 2 with a test agent, the rats were tested.

To test for conditioning, a rat was placed in the middle section, and the doors were lifted to give the rats access to the entire box for $20 \mathrm{~min}$. An observer, blind to a rat's history, timed the number of seconds that the rat spent on each side. The third block of the procedure was the same as the second.

\section{Data Reduction and Statistics}

We took the relatively direct measure of time on the side of putative conditioning as the data for analyses. These data conform to a 3 (type of injection) $x 2$ (preferred or nonpreferred side) $\times 3$ (baseline, Test 1 , Test 2) factorial analysis of variance (ANOVA) with repeated measures. The scores of control rats were compared with each of the experimental groups' scores at testing, and rats' scores after conditioning were compared with those at baseline with the appropriate $t$ tests.

\section{RESULTS}

Results are depicted in Figure 1. Rats that had received saline did not modify the time that they spent on either side across the various tests. Rats that had received opioids tended to spend more time in the location of prior drug experience. The ANOVA yielded $F(4,36)=$ 2.6, $\mathrm{p}=.05$, for the critical drug $\mathrm{x}$ trials interaction. The main effect associated with trials was a reliable source of variance $[\mathrm{F}(2,36)=3.2, \mathrm{p}=.05]$, as was the main effect associated with preferred-nonpreferred side of conditioning $[F(1,18)=9.0, p=.008]$. The triple interactions approached statistical significance $[\mathrm{F}(4,36)=$ $2.5, p=.06]$. These results call for more specific analyses.

Dependent $t$ tests comparing baseline scores with Test 1 scores did not yield any value that suggested a reliable CPP. The comparisons of baseline scores with

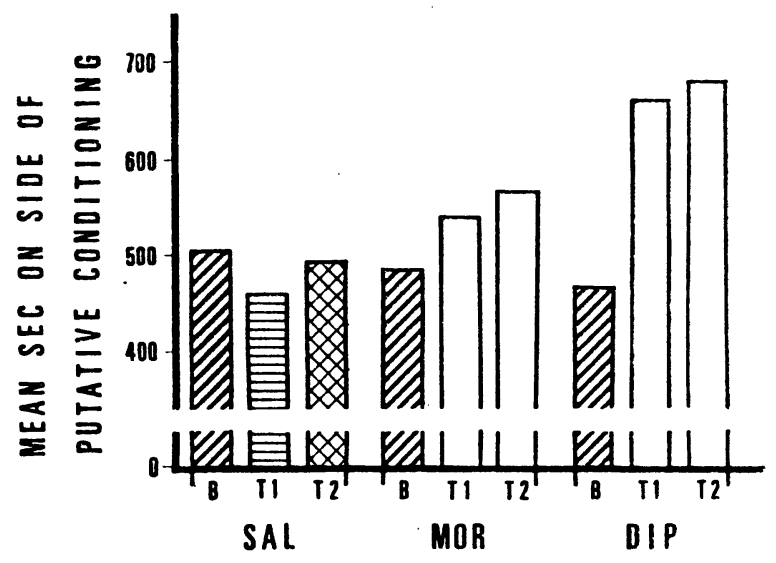

Figure 1. Mean number of seconds on side of putative conditioning collapsed across the baseline side preference. $B$ refers to baseline measure. $\mathrm{T} 1$ and $\mathrm{T} 2$ represent results of the first and second tests, respectively. Rats of SAL received saline on all days, regardless of which side they were placed on. Rats of MOR and DIP received morphine and diprenorphine, respectively, prior to being placed in one side of a box and received saline prior to being placed in the other side.
Test 2 scores also failed to yield results that suggested reliable differences following saline or morphine injections, but did indicate that DIP produced a reliable CPP $[t(7)=3.3, p=.01]$. Tests between scores of rats injected with saline with those of rats injected with DIP at Test 1 yielded $t(14)=2.5, p=.03$; at Test 2 , they yielded $\mathrm{t}(14)=1.9, \mathrm{p}=.08$. Similar tests did not confirm that morphine led to a reliable CPP.

\section{DISCUSSION}

With this limited testing and small dose, MOR did not reliably establish a CPP. Previous tests of MOR, under slightly different circumstances (more days of conditioning or larger doses), have shown that MOR can be used to establish a CPP (Mucha et al., 1980; Rossi \& Reid, 1976). Data indicating a CPP with a dose of a drug clearly indicate that the drug elicits positive affect. The failure to do so reveals little because variables such as time after dosing and length of conditioning sessions are usually arbitrarily chosen and yet remain highly critical. Given these limitations, it is interesting that even with a testing regimen that is only marginally effective with this moderate dose of MOR, the small dose of DIP established a CPP. This dose of DIP increases pressing for brain stimulation, produces no signs of analgesia, and antagonizes the ability of fentanyl to produce analgesia (Pollerberg et al., 1983). These data, therefore, support the idea that analgesia and positive affect produced by opioids may follow from activation of distinct opioid receptors.

\section{REFERENCES}

Bermudez-Rattoni, F., Cruz-Morales, S., \& Reid, L. D. (1983). Addictive agents and intracranial stimulation (ICS): Novel antagonists and agonists of morphine and pressing for ICS. Pharmacology, Biochemistry and Behavior, 18, 777-784.

Bozarth, M. A., Gerber, G. J., \& Wise, R. A. (1980). Intracranial self-stimulation as a technique to study the reward properties of drugs of abuse. Pharmacology, Biochemistry and Behavior, 13(Suppl. 1), 245-247.

Bush, E. D., Bush, M. F., Miller, M. A., \& Reid, L. D. (1976). Addictive agents and intracranial stimulation: Daily morphine and lateral hypothalamic self-stimulation. Physiological Psychology, 4, 79-85.

Esposito, R. U., \& KoRnetsky, C. (1978). Opioids and rewarding brain stimulation. Neuroscience and Behavioral Reviews, 2 , 115-222.

FARBER, P. D., \& REID, L. D. (1976). Addictive agents and intracranial stimulation (ICS): Daily pressing for combinations of positive and negative ICS. Physiological Psychology, 4, 262-268.

Hunter, G. A., JR., \& ReID, L. D. (1983). Assaying addiction liability of opioids. Life Sciences, 33(Suppl. 1), 393-396.

Leibman, J. M. (1983). Discriminating between reward and performance: A critical review of intracranial self-stimulation methodology. Neuroscience and Behavioral Review, 7, 45-72.

Mucha, R. F., van der Kooy, D., O'Shaughnessy, M., \& Bucenieks, P. (1980). Drug reinforcement studied by the use of place conditioning in rat. Brain Research, 243, 91-105.

Pollerberg, G. E., Costa, T., Shearman, G., Herz, A., \& REID, L. D. (1983). Opioid antinociception and positive reinforcement are mediated by different types of opioid receptors. Life Sciences, 33, 1549-1559.

Rossi, N. A., \& REID, L. D. (1976). Affective states associated with morphine injections. Physiological Psychology, 4, 269-274.

(Manuscript received for publication February 27, 1984.) 